\title{
Implementasi Simple Additive Weight untuk Rekomendasi Jabatan Pada Satuan Kerja Perangkat Daerah
}

\section{Implementation of Simple Additive Weight for the Recommendation Position At the Regional Work Units}

\author{
Ni Ketut Dewi Ari Jayanti \\ STMIK STIKOM Bali \\ Jl. Raya Puputan No. 86 Renon Denpasar, telp. 0361244445 \\ daj@stikom-bali.ac.id
}

\begin{abstract}
Abstrak
Untuk membantu tugas dari Kepala Satuan Kerja Perangkat Daerah (SKPD) yang tiap empat tahun ada Pengangkatan Pegawai Negeri Sipil (PNS) dalam jabatan struktural dari masa jabatan pegawai masing-masing, antara lain dimaksudkan untuk membina karier PNS dalam jabatan struktural dan kepangkatan sesuai dengan persyaratan yang ditetapkan dalam peraturan perundangan - undangan pemerintah nomor 100, tentang pengangkatan PNS dalam jabatan struktural. Kepala Satuan Kerja Perangkat Daerah (SPKD) dalam menentukan status jabatan yang akan diberikan kepada PNS yang pantas menduduki jabatan yang dimaksud dalam menentukan jabatan tersebut masih menggunakan cara manual. Dengan perkembangan ilmu pengetahuan perlu dilakukan penelitian yang hasilnya dapat dijadikan dasar bagi pengembangan ke tahap implementasi sistem. Untuk menentukan rekomendasi jabatan seorang PNS, dalam penelitian ini penelitia menggunakan metode Simple Additive Weight (SAW) dalam penentuan rekomendasi jabatan. Dengan diterapkannya metode $S A W$, hasil penelitian ini dapat dijadikan sebagai dasar dalam memberikan solusi bagi Kepala SKPD dalam menentukan jabatan yang direkomendasikan.
\end{abstract}

Kata kunci: Sistem Informasi, Rekomendasi Jabatan, Simple Additive Weight

\section{Abstract}

To help the task of the Head Unit (SKPD) that every four years there Appointment of Civil Servants (PNS) in the structural position of the tenure of employees respectively, among others, intended to build a career civil servant in the structural position and rank in accordance with the requirements set out in legislation - government law number 100, on the appointment of civil servants in structural positions. Head of the regional work units (SKPD) in determining the position status to be given to civil servants who deserve positions referred to in determining the positions are still using manual way. With the development of science is necessary to study the results of which can be used as a basis for the development phase to the implementation of the system. To determine positions on a civil servant, in this study empirically using Simple Additive Weight (SAW) in the determination of positions recommendation. With the implementation of SAW method, the results of this study can be used as a basis to provide solutions for the Head SKPD in determining the recommended positions.

Keywords: Information System, Recomended Position, Simple Additive Weight

\section{PENDAHULUAN}

Satuan Kerja Perangkat Daerah (SPKD) merupakan organisasi/lembaga pada pemerintah daerah yang bertangung jawab kepada gubernur/bupati/walikota dalam rangka penyelenggaraan pemerintah yang terdiri dari sekretaris daerah, dinas daerah dan lembaga teknis daerah, kecamatan, desa dan satuan polisi pramong praja sesuai dengan kebutuhan daerah[1]. Setiap empat tahun ada Pengangkatan Pegawai Negeri Sipil (PNS) dalam jabatan struktural dari masa jabatan pegawai masing-masing, antara lain dimaksudkan untuk membina 
karier PNS dalam jabatan struktural dan kepangkatan sesuai dengan persyaratan yang ditetapkan dalam peraturan perundangan[2].

Peraturan Pemerintah Nomor 100, tentang Pengangkatan Pegawai Negeri Sipil Dalam Jabatan Struktural, Dalam suatu jabatan dilaksanakan berdasarkan prinsip profesionalisme sesuai dengan kompetensi, prestasi kerja, dan jenjang pangkat yang ditetapkan untuk jabatan itu serta syarat obyektif lainnya tanpa membedakan jenis kelamin, suku, agama, ras atau golongan, jabatan struktural hanya dapat diduduki oleh mereka yang berstatus sebagai PNS. Calon Pegawai Negeri Sipil (CPNS), Pegawai Kontrak, dan Pegawai honorer tidak dapat diangkat dalam jabatan struktural. Anggota Tentara Nasional Indonesia dan Anggota Kepolisian Negara hanya dapat diangkat dalam jabatan struktural apabila telah beralih status menjadi PNS, kecuali ditentukan lain dalam peraturan perundangan berstatus Pegawai Negeri Sipil, serendahrendahnya memiliki pangkat satu tingkat dibawah jenjang pangkat yang ditentukan, memiliki kualifikasi dan tingkat pendidikan yang ditentukan, semua unsur penilaian prestasi kerja bernilai baik dalam dua tahun terakhir, memiliki kompetensi jabatan yang diperlukan, sehat jasmani dan rohani[3].

Berdasarkan penjabaran diatas di dapatkan beberapa masalah yang dialami oleh Kepala Satuan Kerja Perangkat Daerah (SPKD) dalam menentukan status jabatan yang akan diberikan kepada PNS yang pantas menduduki jabatan yang dimaksud dalam menentukan jabatan tersebut. Seperti halnya Kepala Satuan Kerja Perangkat Daerah (SPKD) Biro Perekonomian dan Pembangunan (Biro Ekbang) Setda Provinsi Bali masih menggunakan cara manual. Dalam memudahkan pengambilan keputusan ini peneliti melakukan penelitian dimana menggunakan Metode Simple Additive Weight (SAW) dalam menentukan rekomendasi jabatan pada Satuan Kerja Perangkat Daerah (SPKD).

\section{METODE PENELITIAN}

Adapun tahapan-tahapan yang akan dilaksanakan adalah sebagai berikut:

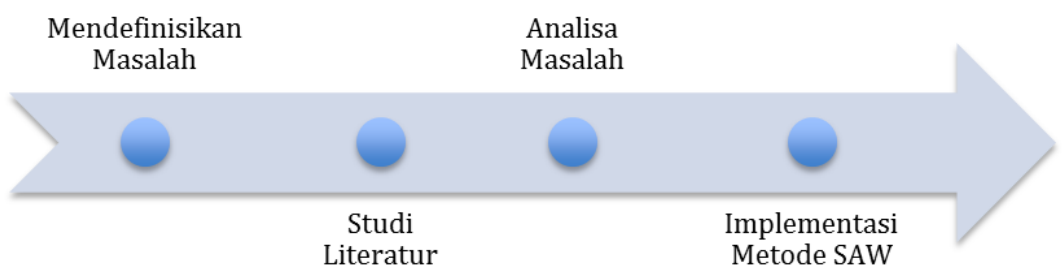

Gambar 1. Alur Penelitian

\subsection{Mendefinisikan Masalah}

Mendifinisikan masalah merupakan tahapan menentukan permasalahan yang ada berkaitan dengan penentuan rekomendasi jabatan pada Satuan Kerja Perangkat Daerah (SKPD). Berdasarkan latar belakang yang diuraikan diatas, dapat diketahui bahwa definisi masalah yang diangkat adalah bagaimana menggunakan metode Simple Additive Weight (SAW) dalam masalah penentuan rekomendasi jabatan.

\subsection{Studi Literatur}

Tahap ini melakukan pengumpulan materi yang berasal dari tulisan-tulisan karya ilmiah, artikel populer, serta tanggapan dari praktisi dan profesional mengenai Satuan Kerja Perangkat Daerah (SPKD) dan metode Simple Additive Weight (SAW).

\subsubsection{Satuan Kerja Perangkat Daerah (SPKD)}

Organisasi/lembaga pada pemerintah daerah yang bertangung jawab kepada gubernur/bupati/walikota dalam rangka penyelenggaraan pemerintah yang terdiri dari sekretaris daerah, dinas daerah dan lembaga teknis daerah, kecamatan, desa dan satuan polisi pramong praja sesuai dengan kebutuhan daerah[1].

\subsubsection{Kenaikan Pangkat PNS}


Pangkat adalah kedudukan yang menunjukkan tingkatan seseorang Pegawai Negeri Sipil berdasarkan jabatannya dalam rangkaian susunan kepegawaian dan digunakan sebagai dasar penggajian. Kenaikan pangkat adalah penghargaan yang diberikan atas prestasi kerja dan pengabdian Pegawai Negeri Sipil terhadap Negara, serta sebagai dorongan kepada Pegawai Negeri Sipil untuk lebih meningkatkan prestasi kerja dan pengabdiannya. Agar kenaikan pangkat dapat dirasakan sebagai penghargaan, maka kenaikan pangkat harus diberikan tepat pada waktunya dan tepat kepada orangnya.

Setiap pegawai baru yang dilantik atau diputuskan sebagai Pegawai Negeri Sipil / PNS baik di pemerintah pusat maupun daerah akan diberikan Nomor Induk Pegawai atau NIP yang berjumlah 18 dijit angka, golongan dan pangkat sesuai dengan tingkat pendidikan yang diakui. Masa kerja untuk kenaikan pangkat pertama Pegawai Negeri Sipil dihitung sejak pengangkatan sebagai Calon Pegawai Negeri Sipil. Kenaikan pangkat dilaksanakan berdasarkan sistem kenaikan pangkat reguler dan sistem kenaikan pangkat pilihan. Kenaikan Pangkat Reguler Kenaikan pangkat reguler diberikan kepada Pegawai Negeri Sipil yang tidak menduduki jabatan struktural atau jabatan fungsional tertentu dan diberikan sepanjang tidak melampaui pangkat atasan langsungnya. Kenaikan pangkat reguler ini diberikan sekurang-kurangnya telah 4 tahun dalam pangkat terakhir dan pangkat tertingginya ditentukan oleh pendidikan tertinggi yang dimilikinya.

\subsubsection{Pengangkatan dalam Jabatan Struktural}

Pengangkatan Pegawai Negeri Sipil (PNS) dalam jabatan struktural antara lain dimaksudkan untuk membina karier PNS dalam jabatan struktural dan kepangkatan sesuai dengan persyaratan yang ditetapkan dalam peraturan perundangan yang berlaku. Pengangkatan Pegawai Negeri Sipil (PNS) dalam suatu jabatan dilaksanakan berdasarkan prinsip profesionalisme sesuai dengan kompetensi, prestasi kerja, dan jenjang pangkat yang ditetapkan untuk jabatan itu serta syarat obyektif lainnya tanpa membedakan jenis kelamin, suku, agama, ras atau golongan. Jabatan struktural hanya dapat diduduki oleh mereka yang berstatus sebagai PNS. Calon Pegawai Negeri Sipil tidak dapat diangkat dalam jabatan struktural. Anggota Tentara Nasional Indonesia dan Anggota Kepolisian Negara hanya dapat diangkat dalam jabatan struktural apabila telah beralih status menjadi PNS, kecuali ditentukan lain dalam peraturan perundangan.

\subsubsection{Pengangkatan dalam Jabatan Fungsional}

Jabatan fungsional adalah kedudukan yang menunjukkan tugas, tanggung jawab, wewenang dan hak seorang Pegawai Negeri Sipil dalam suatu satuan organisasi yang dalam pelaksanaan tugasnya didasarkan pada keahlian/dan atau keterampilan tertentu serta bersifat mandiri. Jabatan fungsional pada hakekatnya adalah jabatan teknis yang tidak tercantum dalam struktur organisasi, namun sangat diperlukan dalam tugas-tugas pokok dalam organisasi Pemerintah. Jabatan fungsional Pegawai Negeri Sipil terdiri atas jabatan fungsional keahlian dan jabatan fungsional keterampilan. Jabatan fungsional dan angka kredit jabatan fungsional ditetapkan oleh Menteri yang bertanggung jawab di bidang pendayagunaan aparatur negara dengan memperhatikan usul dari pimpinan instansi pemerintahan yang bersangkutan, yang selanjutnya bertindak sebagai pembina jabatan fungsional. Jabatan fungsional terdiri atas Jabatan Fungsional Terampil dan Jabatan Fungsional Ahli [4].

Pembebasan sementara, pemberhentian dari, dan pengangkatan kembali dalam jabatan fungsional ditetapkan dengan keputusan pejabat yang berwenang menurut ketentuan peraturan perundang-undangan yang berlaku. Jabatan fungsional Pegawai Negeri Sipil dikelompokkan dalam rumpun-rumpun jabatan fungsional. Rumpun jabatan fungsional adalah himpunan jabatan-jabatan fungsional yang mempunyai fungsi dan tugas yang berkaitan erat satu sama lain dalam melaksanakan salah satu tugas umum pemerintahan. Rumpun jabatan fungsional ditetapkan dengan Keputusan Presiden. Jabatan-jabatan di dalam suatu rumpun jabatan dapat berkembang sesuai perkembangan ilmu dan teknologi. Rumpun jabatan fungsional Pegawai Negeri Sipil ditetapkan dengan Keputusan Presiden Nomor 87 Tahun 1999 [4].

\subsubsection{Metode Simple Additive Weight (SAW)}


Salah satu metode penyelesaian masalah MADM adalah dengan menggunakan metode Simple Additive Weighting (SAW). Metode SAW sering juga dikenal istilah metode penjumlahan terbobot. Konsep dasar metode SAW adalah mencari penjumlahan terbobot dari rating kinerja pada setiap alternatif dari semua atribut [5]. Metode SAW membutuhkan proses normalisasi matriks keputusan (X) ke suatu skala yang dapat diperbandingkan dengan semua rating alternatif yang ada [6]. Metode SAW diberikan persamaan sebagai berikut :

$r_{i j}=\frac{x_{i j}}{\max _{i} x_{i j}} \rightarrow \mathrm{Jika} \mathrm{j}$ adalah attribute keuntungan (benefit)

$r_{i j}=\frac{\min _{i} x_{i j}}{x_{i j}} \rightarrow$ Jika j adalah attribute Biaya (Cost)

Dimana $r_{i j}$ adalah rating kinerja ternormalisasi dari alternatif $A_{i}$ pada atribut $C_{j} ; i=1,2, \ldots, m$ dan $j=1,2, \ldots, n$. Nilai preferensi untuk setiap alternatif $\left(V_{i}\right)$ diberikan sebagai berikut:

$V^{1}=\sum_{j=1}^{n} W_{\mathrm{j}} \mathrm{R}_{\mathrm{ij}}$

Keterangan:

$\mathrm{V}_{1}$ : nilai preferensi

$\mathrm{W}_{\mathrm{j}}$ : bobot rangking

$\mathrm{R}_{\mathrm{ij}}$ : rating kerja ternormalisasi

Nilai Vi yang lebih besar mengindikasikan bahwa altenatif A1 lebih terpilih.

Langkah-langkah dari metode SAW adalah[6]:

1. Menentukan kriteria-kriteria yang akan dijadikan acuan dalam pengambilan keputusan, yaitu C.

2. Menentukan rating kecocokan setiap alternatif pada setiap kriteria.

3. Membuat matriks keputusan berdasarkan kriteria (C),kemudian melakukan normalisasi matriks berdasarkan persamaan yang disesuaikan dengan jenis atribut (atribut keuntungan ataupun atribut biaya) sehingga diperoleh matriks ternormalisasi $\mathrm{R}$.

4. Hasil akhir diperoleh dari proses perankingan yaitu penjumlahan dari perkalian matriks ternormalisasi $\mathrm{R}$ dengan vector bobot sehingga diperolehnilai terbesar yang dipilih sebagai alternatif terbaik (A) sebagai solusi .

Kelebihan dari model Simple Additive Weighting (SAW) dibandingkan dengan model pengambilan keputusan yang lain terletak pada kemampuannya untuk melakukan penilaian secara lebih tepat karena didasarkan pada nilai kriteria dan bobot preferensi yang sudah ditentukan, selain itu SAW juga dapat menyeleksi alternatif terbaik dari sejumlah alternatif yang ada karena adanya proses perankingan setelah menentukan nilai bobot untuk setiap atribut [6].

2.3 Analisa Masalah

Melakukan proses analisa terhadap permasalahan yang dibahas, dan menentukan metode yang dipilih sebagai metode yang digunakan pada permasalahan penentuan rekomendasi jabatan. Dalam penelitian ini, studi kasus penentuan rekomendasi jabatan pada Satuan Kerja Perangkat Daerah (SPKD) Biro Perekonomian dan Pembangunan Setda Provinsi Bali.

Saat ini masalah yang dialami oleh Kepala Biro adalah dalam menentukan status jabatan yang akan diberikan kepada PNS yang layak menduduki jabatan yang dimaksud. Dalam menentukan jabatan tersebut Kepala Biro masih menggunakan cara manual. Untuk memudahkan pengambilan keputusan ini diterapkan suatu algoritma atau metode dalam penentuan 
rekomendasi jabatan. Metode yang diimplementasikan adalah metode Simple Additive Weight (SAW).

2.4 Implementasi Metode SAW

Penerapan metode Simple Additive Weight (SAW) dilakukan berdasarkan hasil yang diperoleh dari tahap analisa masalah. Dalam sub bahasan ini akan dibahas mengenai kriteria yang digunakan dalam penentuan rekomendasi jabatan serta perhitungan metode Simple Additive Weight (SAW) berdasar pada kriteria tersebut.

\subsubsection{Penetapan Kriteria}

Adapun kriteria yang digunakan dalam penentuan rekomendasi jabatan adalah sebagai berikut :

a. Kompetensi (C1) : Berupa Kemampuan kerja setiap individu yang mencakup aspek pengetahuan, keterampilan, yang di tuntut oleh jabatan tertentu.

b. Prestasi Kerja (C2) : Berupa hasil kerja yang di capai oleh setiap pegawai dan satuan organisasi dengan sasaran dan perilaku kerja di sesuaikan dengan daftar penilaian kerja pegawai.

c. Jenjang Jabatan (C3): Berupa golongan yang menentukan jabatan itu

d. Test Jabatan (C4) : Adalah menyediakan pilihan yang lebih luas bagi organisasi untuk memperoleh kandidat yang kompeten dan memberi kesempatan kepada para pegawai untuk di angkat dalam jabatan struktural, Berupa Pilihan antara Sudah atau tidaknya Melakukan test jabatan.

e. Masa Kerja PNS (C5) : Adalah masa kerja yang di hitung sejak diangkat menjadi CPNS s ampai dengan batas usia pensiun menjadi PNS.

Penetapan bobot untuk masing-masing kriteria ditetapkan berdasar pada tabel berikut :

Tabel 1 Bobot masing-masing Kriteria

\begin{tabular}{cc}
\hline Kriteria & Bobot \\
\hline $\mathrm{C} 1$ & 0.2 \\
\hline $\mathrm{C} 2$ & 0.25 \\
\hline $\mathrm{C} 3$ & 0.2 \\
\hline $\mathrm{C} 4$ & 0.2 \\
\hline $\mathrm{C} 5$ & 0.15 \\
\hline
\end{tabular}

\subsubsection{Perhitungan dengan Menggunakan Simple Additive Weight (SAW)}

Sebagai contoh, akan ditentukan kenaikan jabatan suatu SKPD dan terdapat 3 orang pegawai yang direkomendasikan, dimana representasi dari pegawai dinyatakan sebagai alternatif maka alternatif pertama adalah A1, alternatif kedua A2 dan alternatif ketiga A3. Dengan menggunakan Simple Additive Weight (SAW), berikut adalah nilai-nilai kriteria dari setiap alternatif/ pegawai :

Tabel 2 Perhitungan Kriteria

\begin{tabular}{cccccc}
\hline Pegawai/ & \multicolumn{5}{c}{ Kriteria } \\
\cline { 2 - 6 } Alternatif & $\mathrm{C} 1$ & $\mathrm{C} 2$ & $\mathrm{C} 3$ & $\mathrm{C} 4$ & $\mathrm{C} 5$ \\
\hline A1 & 56 & 87 & 60 & 65 & 80 \\
\hline A2 & 67 & 87 & 83 & 67 & 80 \\
\hline A3 & 80 & 83 & 60 & 67 & 81 \\
\hline
\end{tabular}

Berdasarkan nilai masing-masing kriteria dari pegawai yang direkomendasikan, selanjutnya dilakukan normalisasi dengan rumus sebagai berikut :

$r_{i j}=\frac{x_{i j}}{\max _{i} x_{i j}} \rightarrow$ Jika j adalah attribute keuntungan (benefit)

$r_{i j}=\frac{\min _{i} x_{i j}}{x_{i j}} \rightarrow$ Jika j adalah attribute biaya $($ Cost $)$

Dimana $\mathrm{r}_{\mathrm{ij}}$ adalah rating kinerja ternormalisasi dari alternatif $\mathrm{Ai}$ pada atribut $\mathrm{Cj}$; $\mathrm{i}=1,2, \ldots, \mathrm{m}$ dan $\mathrm{j}=1,2, \ldots, \mathrm{n}$. Berikut adalah hasil normalisasi : 
$\mathrm{r}=\left[\begin{array}{ccccc}0.7 & 1 & 0.72 & 0.97 & 0.99 \\ 0.84 & 1 & 1 & 1 & 0.99 \\ 1 & 1.95 & 0.72 & 1 & 1\end{array}\right]$ berikut:

Selanjutnya dihitung nilai preferensi untuk setiap alternatif (Vi) dengan rumus sebagai

$$
V^{1}=\sum_{j=1}^{n} W_{j} R_{i j}
$$

Keterangan:

$\mathrm{V}_{1}$ : nilai preferensi

$\mathrm{W}_{\mathrm{j}}$ : bobot rangking

$\mathrm{R}_{\mathrm{ij}}$ : rating kerja ternormalisasi

Nilai Vi yang lebih besar mengindikasikan bahwa altenatif A1 lebih terpilih. Berikut adalah perhitungan nilai preferensi untuk masing-masing alternatif.

1. Pegawai Pertama sebagai alternatif pertama (A1), maka nilai preferensinya (V1) adalah : $\mathrm{V} 1=(0.7) \cdot(0.2)+(1) \cdot(0.25)+(0.72) \cdot(0.2)+(0.97) \cdot(0.2)+(0.99) \cdot(0.15)=0.876=0.88$

2. Pegawai Kedua sebagai alternatif kedua (A2), maka nilai preferensinya (V2) adalah : $\mathrm{V} 2=(0.84) \cdot(0.2)+(1) \cdot(0.25)+(1) \cdot(0.2)+(1) \cdot(0.2)+(0.99) \cdot(0.15)=0.965=0.97$

3. Pegawai Ketiga sebagai alternatif ketiga (A3), maka nilai preferensinya (V3) adalah : $\mathrm{V} 3=(1) \cdot(0.2)+(1.95) \cdot(0.25)+(0.72) \cdot(0.2)+(1) \cdot(0.2)+(1) \cdot(0.15)=0.933=0.93$

Berdasarkan nilai preferensi yang diperoleh oleh masing-masing alternatif yang dalam hal ini adalah pegawai yang direkomendasikan, maka dapat dilihat bahwa pegawai/ alternatif pertama memperoleh nilai 0.88 , pegawai/ alternatif kedua memperoleh nilai 0.97 dan pegawai/ alternatif ketiga memperoleh nilai 0.93 . Nilai preferensi tertinggi diperoleh oleh pegawai/ alternatif kedua, sehingga dari tiga pegawai yang direkomendasikan untuk kenaikan jabatan, pegawai kedua dapat direkomendasikan untuk memperoleh kenaikan jabatan.

\section{HASIL DAN PEMBAHASAN}

Pada bagian ini dibahas mengenai tahap perancangan dan impelementasi sistem rekomendasi jabatan dengan menerapkan metode Simple Additive Weight. Perancangan terdiri atas alur sistem menggunakan tools flowchart, alur proses menggunakan tools Data Flow Diagram, perancangan basis data menggunakan tools Entity Relationship Diagram. Implementasi sistem menyajikan screenshoot sistem yang dibangun.

3.1 Perancangan Sistem

Seperti penjabaran sebelumnya, pada perancangan sistem terdiri atas alur sistem, alur proses dan perancangan basis data. Berikut penjabaran masing-masing.

3.1.1 Alur sistem

Sistem ini di mulai ketika pegawai memasukan biodata kemudian pimpinan memberikan bobot pada setiap kriteria biodata tersebut, kemudian diproses mengunakan metode Simple Additive Weight maka di dapatkan hasil pegawai yang akan di rekomendasikan jabatanya. Berikut gambaran alur sistemnya. 


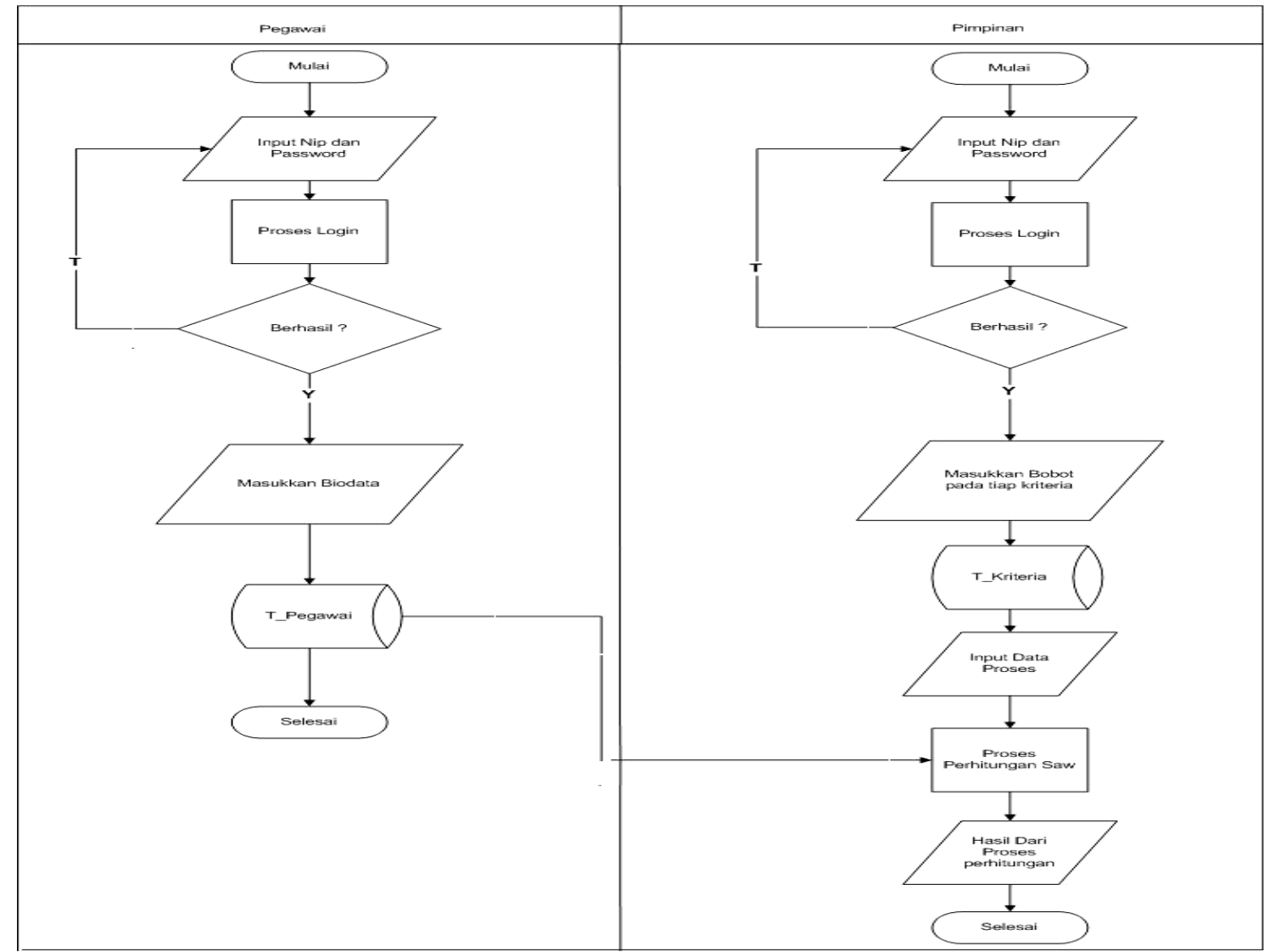

Gambar 2. Alur Sistem

\subsubsection{Alur Proses}

Diagram Konteks merupakan titik awal dari alur proses. Diagram ini dapat memberikan gambaran umum sebuah sistem yang akan dibuat, dan menunjukkan batasan dari sistem [7]. Pada gambar diagram konteks terdapat 2 entitas dan 1 proses yaitu entitas pimpinan, entitas pegawai dan 1 proses sitem pendukung keputusan. Entitas pimpinan memiliki 8 arus data yang menuju proses, dan dari proses menuju ke entitas pimpinan memiliki 8 arus data. Pada entitias pegawai memiliki 4 arus data yang menuju ke proses dan dari proses menuju ke entitas pegawai memiliki 4 arus data. Berikut gambaran Data Flow Diagram.

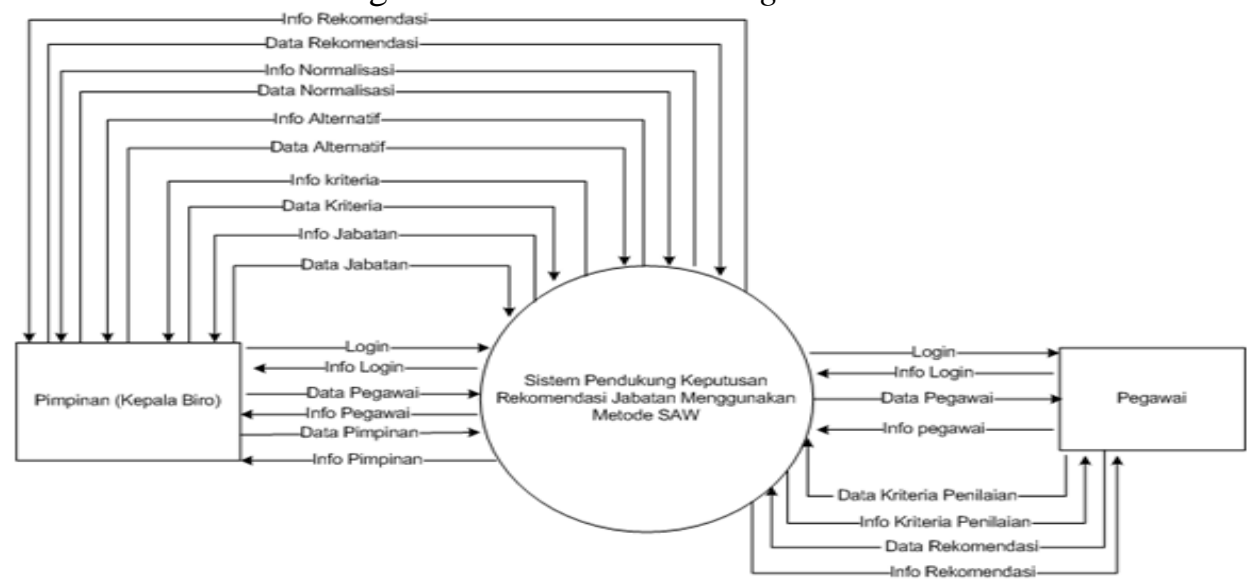

Gambar 3 Diagram Konteks 
Selanjutnya DFD Level 0 merupakan penjabaran dari diagram konteks. Pada level ini dipecah menjadi 3 proses yaitu proses login, proses pengolahan data dan proses rekomendasi data. Data store yang terlibat terdiri atas tb_login, tb_pimpinan, tb_pegawai, tb_jabatan, tb_kriteria, tb_alternatif, tb_normalisasi dan tb_rekomendasi. Berikut gambaran DFD level 0.

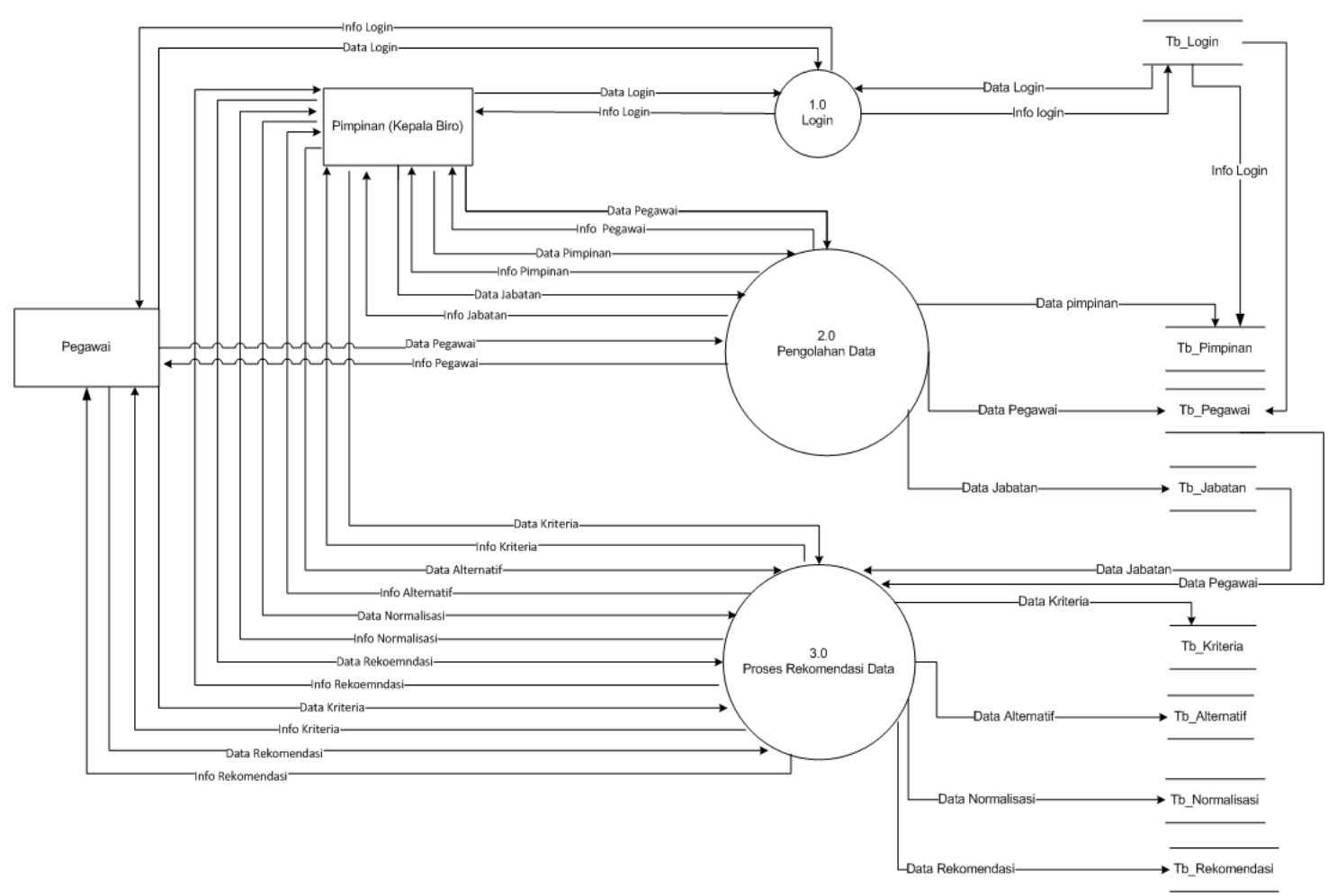

\subsubsection{Perancangan Basis Data}

Gambar 4 DFD Level 0

Entity Relationship Diagram (ERD) menggambarkan relasi dari semua entitas yang ada menjadi satu kesatuan yang saling berkaitan [8]. ERD sangat membantu dalam menentukan seperti apa sistem yang akan kita buat nantinya dan juga memudahkan apabila terjadi perubahan aplikasi yang telah dibentuk. Adapun perancangan basis data dari implementasi sistem dapat dilihat pada gambar berikut :

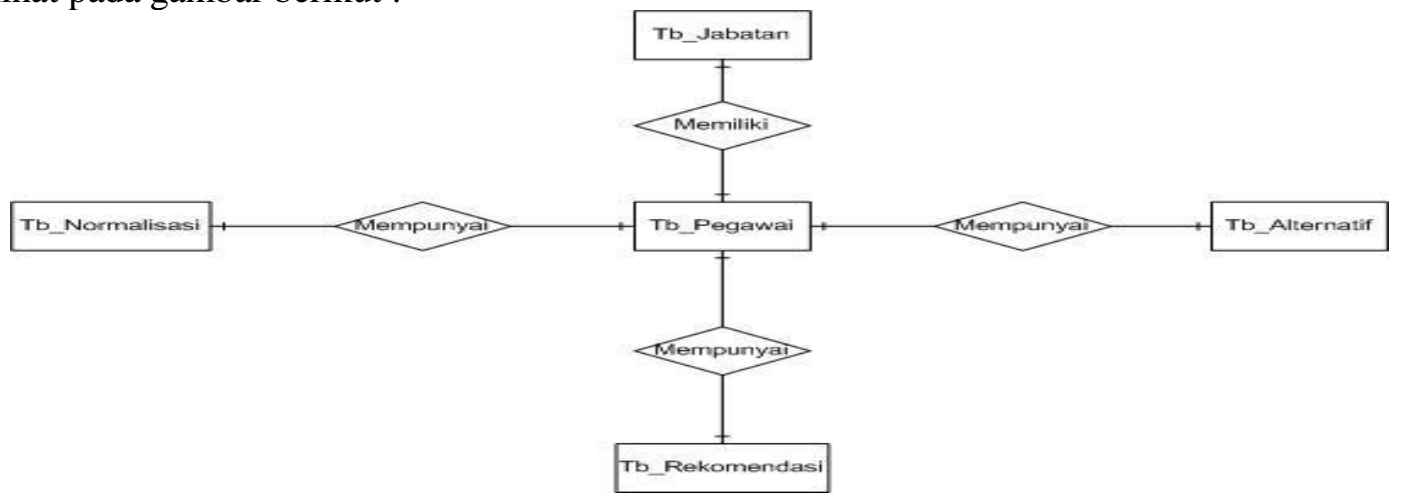

Gambar 5 Entity Relationship Diagram

Pada gambar di atas, Entity Relationship Diagram memiliki 5 entitas yaitu Tb_Jabatan, Tb_Normalisasi, Tb_Rekomendasi, Tb_Alternatif, Tb_Pegawai semuanya memiliki cardinality rasio constraint one to one.

3.2 Implementasi Sistem

Sesuai dengan apa yang sudah direncanakan pada tahap perancangan sistem rekoemendasi jabatan mengunakan metode SAW ini di bagi menjadi 2 level user yaitu pegawai dan pimpinan. Berikut penjabaran hasil dari sistem yang dibangun. 
Sebelum mengunakan sistem ini user harus melakukan login agar dapat menuju halaman pimpinan atau pegawai yang membedakan user itu pegawai atau pimpinan adalah (Nomer Induk Pegawai) NIP. Berikut tampilan halaman login.

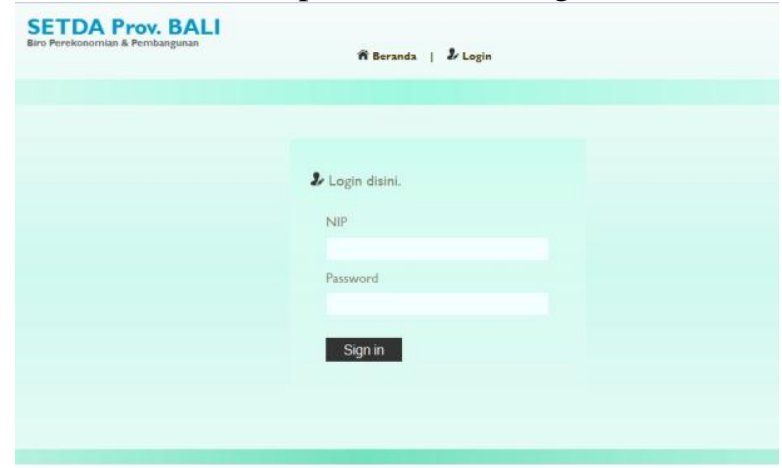

Gambar 6 Halaman Login

Jika login mengunakan NIP pegawai maka akan menuju ke halaman pegawai di situ akan terlihat foto pegawai siapa yang login itu dimana di halaman pegawai ada empat menu halaman, profil pegawai ,halaman kriteria penilaian ,dan halaman rekoemndasi untuk melihat hasil rekoemendasi. Berikut tampilan halaman pegawai.

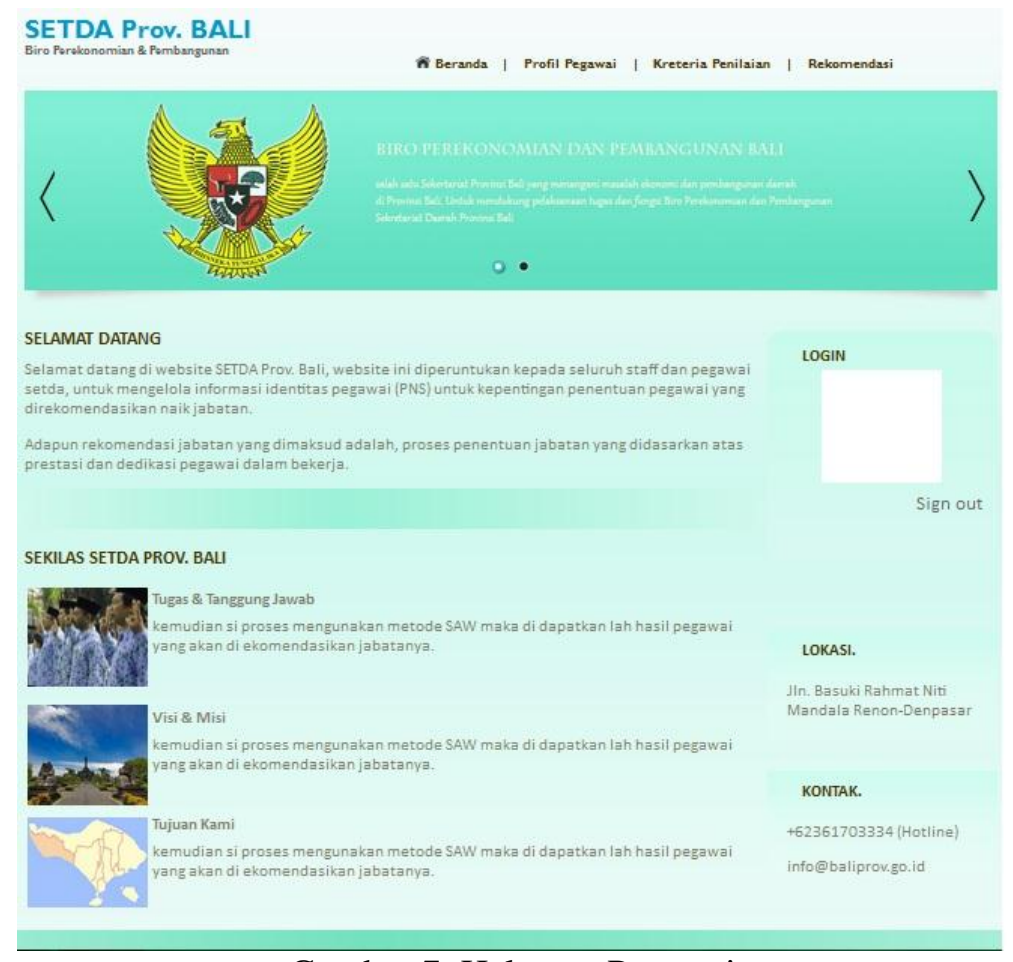

Gambar 7. Halaman Pegawai

Untuk melihat kriteria dan nilai persentasi penilaian, pegawai dapat melihatnya melalui halaman kriteria penilaian. Sedangkan untuk menampilkan hasil dari proses perhitungan yang dilakukan oleh pimpinan pegawai yang mendapatkan rekomendasi jabatan dapat dilihat melalui halaman rekomendasi pegawai. Berikut tampilan halaman kriteria penilaian dan halaman rekomendasi pegawai. 


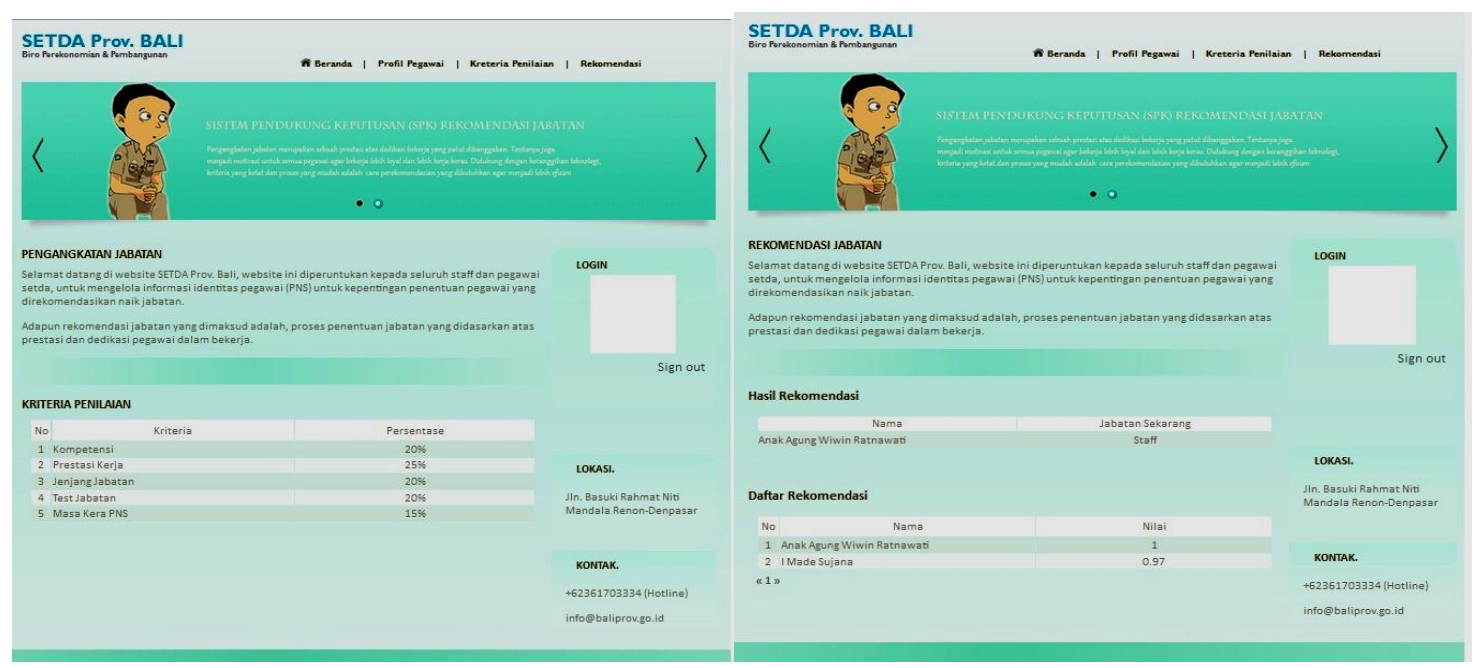

Gambar 8. Halaman Kriteria Penilaian dan Rekomendasi Pegawai

Selanjutnya jika user melakukan Login dengan NIP pimpinan makan akan masuk ke halaman pimpinan tampilanya hampir sama dengan halaman pegawai cuma ada tambahan menu yaitu halaman pengolahan data pegawai dan jabatan untuk menambah dan merubah data pegawai serta jabatan, halaman penentuan rekomendasi untuk melakukan perhitungan rekomendasi jabatan dengan metode SAW. Berikut tampilan halaman pengolahan pegawai dan jabatan serta halaman penentuan rekomendasi.

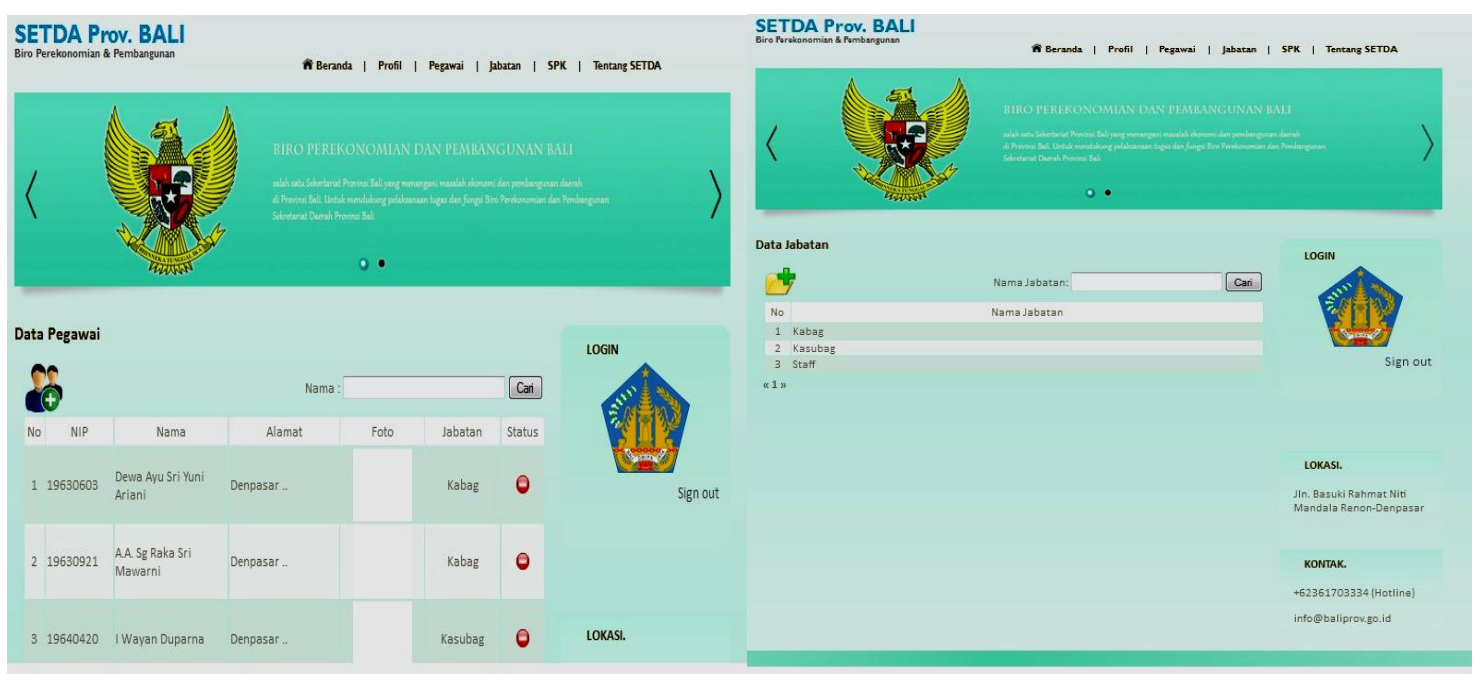

Gambar 9. Halaman Pengolahan Data Pegawai dan Jabatan

Pada halaman penentuan rekomendasi Pimpinan dapat menambahkan penilaian pada tambah alternatif, dapat melihat nilai pada setiap kriteria pada kriteria, dan melakukan proses perhitungan pada proses penentuan rekomendasi jabatan. 


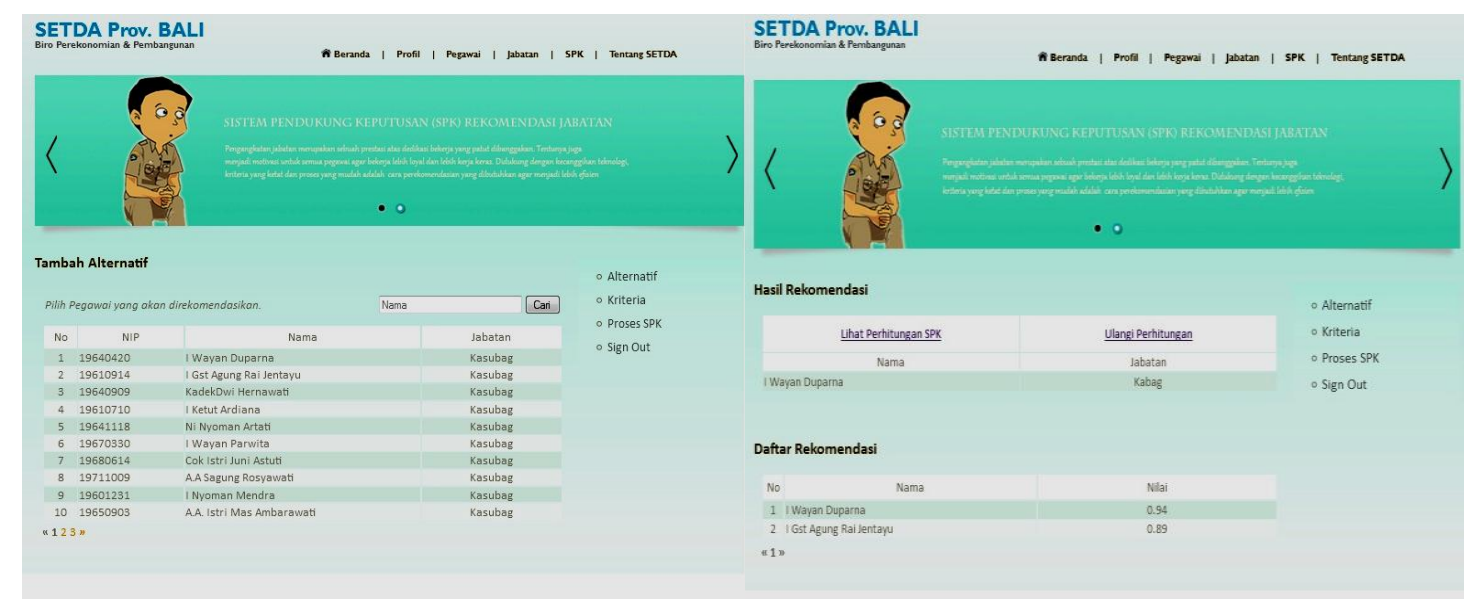

Gambar 10. Halaman Penentuan Rekomendasi

\section{KESIMPULAN}

Kesimpulan yang dapat diambil dari penelitian ini adalah yang pertama, berdasarkan analisa permasalahan yang dilakukan telah berhasil ditetapkan 5 kriteria yang dijadikan sebagai dasar dalam penentuan rekomendasi kenaikan jabatan pada SKPD. Simpulan kedua adalah Simple Additive Weight (SAW) dapat menyelesaikan permasalahan penentuan rekomendasi kenaikan jabatan dengan menghitung nilai preferensi untuk masing-masing alternatif dan alternatif yang memiliki nilai preferensi paling tinggi mengindikasi bahwa alternatif tersebut lebih direkomendasikan untuk memperoleh kenaikan jabatan.

\section{SARAN}

Penelitian ini masih memiliki kekurangan yang dapat diperbaiki dan dikembangkan untuk menghasilkan penelitian yang lebih baik lagi. Berikut beberapa hal yang dapat dilakukan untuk pengembangan penelitian adalah perlu ditambahkan fitur - fitur lain agar sistem ini lebih sempurna, misalnya mampu mencetak laporan kenaikan jabatan ataupun dapat memberikan notifikasi pada pegawai jika beliau mendapat rekomendasi jabatan melalui sms. Selain itu saran yang dapat diberikan disini adalah menggunakan metode yang berbeda misalnya TOPSIS, dan selanjutnya melakukan perbandingan hasil perhitungan berdasarkan metode SAW dan TOPSIS

\section{UCAPAN TERIMA KASIH}

Penulis mengucapkan terima kasih kepada Pimpinan STMIK STIKOM Bali yang telah memberi dukungan financial terhadap penelitian ini.

\section{DAFTAR PUSTAKA}

[1] http://pustaka.pu.go.id , Direktori istilah Bidang Pekerjaan Umum : SKPD, diakses pada tanggal 22 Juni 2015.

[2] http://www.bkn.go.id, Kenaikan Pangkat PNS , diakses pada tanggal 22 Juni 2015.

[3] http://www.bkn.go.id, Pengangkatan dalam Jabatan Struktural , diakses pada tanggal 22 Juni 2015.

[4] http://www.bkn.go.id , Pengangkatan dalam Jabatan Fungsional , diakses pada tanggal 22 Juni 2015.

[5] Fishburn, P. C. , 1967, A Problem-based Selection of Multi-Attribute Decision Making Methods, Blackwell Publisihing, New Jersey. 
[6] Kusumadewi, Sri, 2006, Fuzzy Multi-Attribute Decision Making (Fuzzy MADM),Graha Ilmu,Yogyakarta.

[7] Jogiyanto, H. 2005, Analisa dan Desain Sistem Informasi. Yogyakarta. Penerbit Andi Offset.

[8] Kusrini, 2007, Strategi Perancangan dan Pengolahan Basis Data. Penerbit Andi: Yogyakarta. 